CASE OF

RUPTURE OF THE UTERUS AND VAGINA WITH ESCAPE OF THE FETUS INTO

THE ABDOMINAL CAVITY; ABDOMINAL SECTION.

By SURGEON-MAJOR J. G. PILCHER, F.R.C.S., CIVIL SURGEON, DARJEELING.

NAsiboN, aged twenty-five, was admitted into the Darjeeling Dispensary during the afternoon of May 1st, having been two days in labour. The native dhoimidwife-who attended the case stated that she had made out a face presentation, which had suddenly disappeared on the morning of the day of admission. The patient stated that she had been delivered of four children previously, all of whom had been born dead. She also stated, but with some hesitation, that they were all born at full term and that she was now at full term ; that her pains ceased in the morning.

On admission, the woman was in a state of extreme exhaustion, the pulse was small and thready, she complained of severe pain in the abdomen, and had been vomiting frequently. On palpation over the abdomen all parts of the child could be clearly made out. The abdominal walls were very thin, and the child was evidently outside the uterus in the abdominal cavity. On vaginal examination the promontory of the sacrum was felt protruding sharply forwards into the pelvis. Anteriorly there were two angular projections backwards, each situated about two inches outside the symphysis; these were evidently the bodies of the pubes pressed inwards by the weight of the body on the femora during a period of softened bone. To this cause must also have been due the prominence of the sacrum. The antero-posterior diameter of the pelvis was less than two inches. The os uteri could not be felt anywhere, and the vagina was occupied by a fringe-like body, which felt like omentum. With slight traction this was brought outside the vulva, and was seen to be omentum.

A rupture of the parturient canal with escape of the foetus into the abdominal cavity was diagnosed. Surgeon-Major Pilcher having been sent for, arrived about 7 P.M., confirmed the diagnosis which had been made, and determined to perform abdominal section.

Operation. - About 7.30 P.M. the patient was placed under chloroform, and an incision made in the median line of the abdomen from two inches above the umbilicus to just above the symphysis pubis. On opening the peritoneum a large quantity of bloody fluid and small clots escaped, and the uterus was at once seen to be firmly contracted. The placenta then edged forwards and was removed with scarcely any traction, and the body of the foetus lifted out of the abdomen. The uterus was next examined. Its anterior surface was intact, but on lifting it out of the incision it was discovered that the posterior half of the circumference of the vagina was torn away from the cervix. In addition to this lesion there was a rent about three inches long, separating the posterior portion of the cervix from the body of the uterus. The rent in the uterus was then stitched with interrupted catgut sutures, the cavity of the abdomen was sponged out, and as much clot and liquid as could be found were carefully removed. Two large drainage tubes were inserted per vaginam, one into the uterus and the other through the vaginal rent, into the abdominal cavity. The abdominal incision was closed with seven silk sutures, which included the whole thickness of the abdominal wall. The operation was performed under antiseptic precautions, all sponges and instruments having been well soaked in perchloride solution ( 1 in 5000 ) and carbolic acid respectively. The wound was dressed with a thick pad of lint soaked in compound tincture of benzoin. The patient rallied well after the operation and was put to bed, some stimulants having been administered, and hot bottles applied to the feet. Half a grain of morphia was given by the mouth. The patient slept at intervals during the night. Her temperature at $7 \mathrm{~A} . \mathrm{M}$. was $102^{\circ}$, and her pulse very weak. At 8.30 A.M. gasping respiration was noticed, and twenty minims of sulphuric ether were injected hypodermically. At $9.45 \mathrm{~A}$. M. the pulse was imperceptible, and the woman died from exhaustion at $10.45 \mathrm{~A} . \mathrm{M}$.

Remarks. - This case is of interest chiefly on account of the rarity of the condition. The state of the pelvis was identical with that described by Dr. Playfair as due to osteomalacia. The astonishing statement of the patient that she had been delivered of four children at full time would be inexplicable to anyone not knowing the inaccuracy of the native character. It is much to be regretted that the patient herself was not in a condition to afford fuller information as to her previous history, and that her fiiends were too ionorant. The dhoi's statement that she made out a face presentation was doubtless perfectly correct. The outlet of the pelvis being impassable, the occiput was driven through the posterior wall of the vagina. The tear in the cervix must have occurred at the moment when the head passed from the uterus into the vagina. Had the patient been seen in the early morning, when the injury first occurred, she would have had a very much better chance of recovery. As it was, when brought to hospital she was in such a state of exhaustion that the operation was only performed as a last resource, and her recovery was hardly hoped for.

The above account has been kindly written by Dr. Peck of the Indian Medical Service, who assisted at the operation, and without whose help it would have been most difficult to complete the operation. The condition of the woman after the operation was not worse than before it, and had the case come under observation earlier, life would most likely have been saved.

Darjeeling, India.

\section{A duthror}

\section{or}

\section{HOSPITAL PRACTICE, BRITISH AND FOREIGN.}

Nulla autem est alia pro certo noscendi via, nisi quamplurimas et morborum et dissectionum historias, tum aliorum tum proprias collectas habere, et inter se comparare.-MoRgagni De Sed. et Caus. Morb. lib. iv. Procmium.

\section{ST. THOMAS'S HOSPITAL.}

A CASE OF COMPOUND FRACTURE OF THE CRANIUM, WITH DEPRESSION AND ESCAPE OF CEREBRAL MATTER; OPERATION; RECOVERY; REMARKS.

(Under the care of Mr. WILLIAM ANDERSON.)

THE special points of interest in these cases are fully indicated by $\mathrm{Mr}$. Anderson in the remarks appended to each.

The patient, Elizabeth $\mathrm{M}-$ - a child aged eighteen months, was admitted on July 2nd, 1887. It was stated that she had slipped from the arms of an elder sister, and fell over the balustrade down the well of the staircase atriking her head against the ground about twenty feet below. She was picked up in an insensible condition, and brought to the hospital.

On admission she was collapsed and quite unconscious. There was a small scalp wound over the right frontal eminence, and from the contused aperture was escaping a considerable quantity of blood and brain matter intermingled with cerebro-spinal fluid. The temperature was $96^{\circ}$. A short time afterwards chloroform was administered; the external wound, which was in a very dirty condition, was cleansed. Under antiseptic precautions, the aperture was enlarged to the extent of about two inches and a half and the injured surface of bone exposed. A wide fissure was found over the right side of the frontal bone, extending from near the middle line and about one inch and a half above the orbit downwards and outwards into the right temporal fossa, where it was lost; the bone forming the upper edge of the fissure was depressed and separated from the lower edge sufficiently to allow the insertion of the tip of the little finger into the cranial cavity; the gap was occupied by broken-down brain matter, and there was a good deal of oozing of blood from the depth of the wound. The wound was flooded with a weak carbolic solution, and $\mathrm{Mr}$. Anderson removed-partly with a trephine, partly with parrotbeak forceps-a large portion of the depressed bone, leaving an irregularly circular gap of about an inch in diameter. $\mathbb{A}$ ligature was applied to a small anterior meningeal vessel. A drainage tube was then inserted, the external wound was closed as far as the tube would permit, and antiseptic dressings were applied. 